\title{
Integrated Software Environment for Pressurized Thermal Shock Analysis
}

\author{
Dino Araneo,, ${ }^{1}$ Paolo Ferrara, ${ }^{1}$ Fabio Moretti, ${ }^{1}$ Andrea Rossi, ${ }^{1}$ Andrea Latini, ${ }^{1}$ \\ Francesco D'Auria, ${ }^{1}$ and Oscar A. Mazzantini ${ }^{2}$ \\ ${ }^{1}$ Department of Mechanical Nuclear and Production Engineering, University of Pisa, Via Livornese 1291, \\ San Piero a Grado, 56126 Pisa, Italy \\ ${ }^{2}$ Nucleoeléctrica Argentina S.A. (NA-SA), Arribeños 3619, 1429 Buenos Aires, Argentina
}

Correspondence should be addressed to Dino Araneo, d.araneo@ing.unipi.it

Received 8 September 2010; Accepted 23 November 2010

Academic Editor: Juan Pablo Ordonez

Copyright (C) 2011 Dino Araneo et al. This is an open access article distributed under the Creative Commons Attribution License, which permits unrestricted use, distribution, and reproduction in any medium, provided the original work is properly cited.

\begin{abstract}
The present paper describes the main features and an application to a real Nuclear Power Plant (NPP) of an Integrated Software Environment (in the following referred to as "platform") developed at University of Pisa (UNIPI) to perform Pressurized Thermal Shock (PTS) analysis. The platform is written in Java for the portability and it implements all the steps foreseen in the methodology developed at UNIPI for the deterministic analysis of PTS scenarios. The methodology starts with the thermal hydraulic analysis of the NPP with a system code (such as Relap5-3D and Cathare2), during a selected transient scenario. The results so obtained are then processed to provide boundary conditions for the next step, that is, a CFD calculation. Once the system pressure and the RPV wall temperature are known, the stresses inside the RPV wall can be calculated by mean a Finite Element (FE) code. The last step of the methodology is the Fracture Mechanics (FM) analysis, using weight functions, aimed at evaluating the stress intensity factor (KI) at crack tip to be compared with the critical stress intensity factor KIc. The platform automates all these steps foreseen in the methodology once the user specifies a number of boundary conditions at the beginning of the simulation.
\end{abstract}

\section{Introduction}

The RPV has long been considered one of the most reliable components in Pressurized Water Reactors (PWRs). Nowadays a general target for the countries that produce nuclear energy is to extend the operation life of existing plants. From this point of view, the RPV is one of the major components that may limit the useful life of the nuclear power plant. The risk for the RPV structural integrity is connected to the presence of a flaw of relatively large size, a high level of embrittlement due to radiation damage, and the occurrence of a thermal-hydraulic transient inducing strong stresses in the vessel wall. Severe loading conditions are produced during a Pressurized Thermal Shock (PTS) scenario, in which an over cooling in a limited region of the RPV internal surface may induce strong thermal stresses, while the internal pressure being maintained at high thermal level or the system being repressurized during the transient. The main initiating PTS events identified in the literature are Small Break Loss of Coolant Accident (SBLOCA), Main Steam Line Break (MSLB), Loss of Main Feed Water (LOFW), Steam Generator Tube Rupture (SGTR), and Loss Of Heat Sink (LOHS). The transients leading the Nuclear Power Plant (NPP) to a PTS scenario are intrinsically asymmetric, so it is important to avoid any simplification by symmetry in the model used for the analyses. In recent years important progress has been made in the development of analysis methods for the best estimation of the thermal loads and the structure stresses on the vessel wall, needed for an indepth fracture mechanics study. A research activity carried out at Department of Mechanics Nuclear and Production Engineering of the University of Pisa is aimed at developing a computational tool able to perform parametric analysis, assuming various shapes and locations of the flaw in a RPV. 


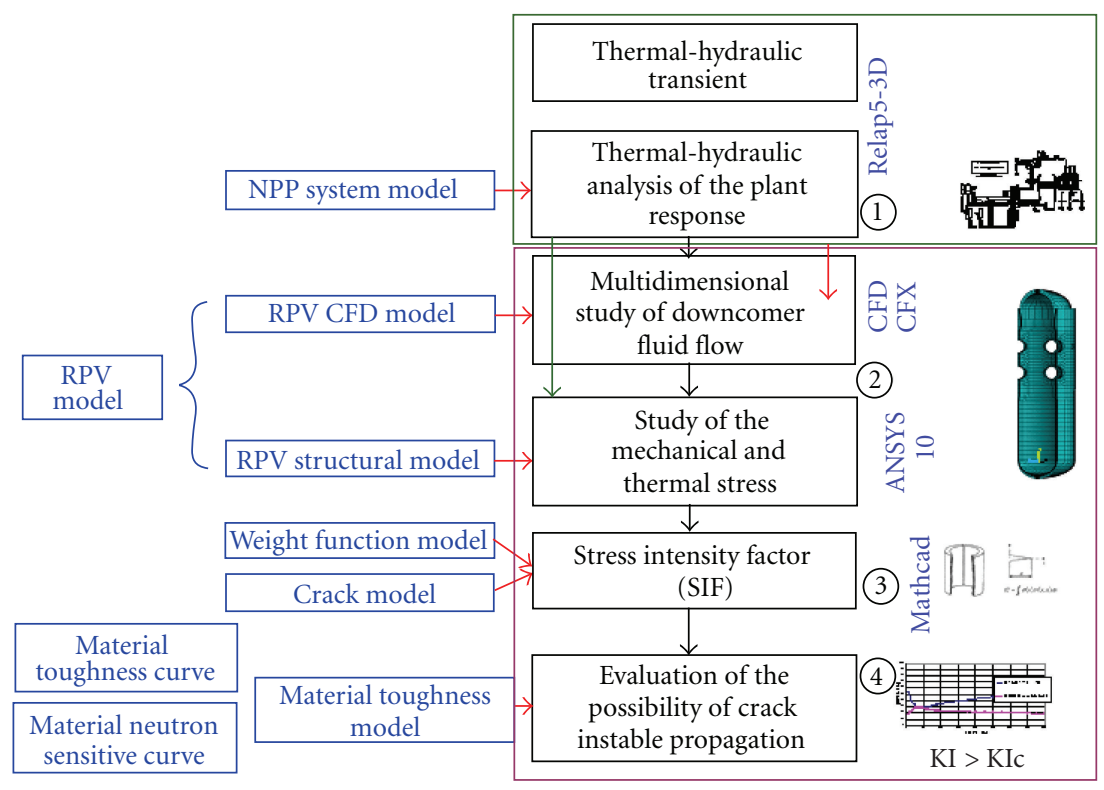

Figure 1: UNIPI methodology for PTS analysis.

\section{UNIPI Methodology for PTS Analysis}

University of Pisa developed a methodology (summarized in Figure 1) concerning the use of a chain of codes for the deterministic analysis of PTS scenario.

The methodology starts with the thermal-hydraulic analysis of the NPP with a System Thermal-Hydraulic (SYS TH) code (such as Relap5-3D, Cathare2, etc.) during a selected transient scenario. The goal of this step is to (roughly) calculate the cooling load induced on the internal RPV wall surface by the Emergency Core Coolant (ECC) injection, and to provide boundary conditions for the next step. The region of interest is represented by the RPV welding lines facing the core region.

The next step consists, for transients with the fluid in single phase, of a 3D analysis of the downcomer flow and of the temperature field in the RPV wall, using a CFD code (possibly with CHT capabilities). An interesting feature of the methodology is represented by the possibility to transfer the RPV wall temperature profile calculated by the SYS TH code to the ANSYS FE model (green arrow in Figure 1). Once the pressure of the system and the temperature distribution in the RPV wall are known during the selected transient, (with the support of SYS TH and CFD codes resp.), a stress analysis can be performed by means of a FE structural mechanics code (such as ANSYS) applied to a complete model ANSYS grid, where both pressure and thermal loads are considered. For this purpose it is needed to transfer main CFD results (in particular: temperature profile) to the ANSYS model, in order to evaluate the thermal stresses inside the RPV. Once the stress profile in the RPV wall is known, FM analysis is then performed by means of weight functions, see [1], for the calculation of the stress intensity factor at crack tip (KI) to be compared with the material fracture toughness curve (KIc), that is, obtained from specific tests, to establish whether crack propagation is stable or unstable and, in the first case, to determine the safety margin (cf. [2]).

\section{PTS Platform: Overview}

UNIPI methodology has been implemented into an Integrated Software Environment (in the following referred to as ISE or "platform") in order to avoid the difficulty connected to the exchange of data among proprietary and non proprietary codes used in the analysis, such as Relap53D, Cathare2, CFX and ANSYS Multiphysics, each code having its own specific format for data input and output (see [3] for Relap5 code).

In fact, manual creation of connections between codes is often a potential source of errors even for the most expert users, because data transfer procedures could be different each time a calculation is performed and then we can suppose that each user could implement his own procedures. Besides these codes are very complex and they offer many different options to the users, most of them are not useful for users' goals, so users should have a lot of experience to choose the right ones. Another problem is that calculations are often very long, so they can take days or weeks and they could be completed in any moment, even during the night, or when users are not at work; so it may cause further delays.

The creation of such tool leads to improvements connected with: standardization of procedures for connecting different codes, simulation time reduction and user effect reduction, because users must interact with the platform only at the beginning of the first step and at the end of the last step of a PTS transient simulation. In fact ISE is able to execute automatically the complete PTS analysis, once the boundary and initial conditions have been given in input to the software. 


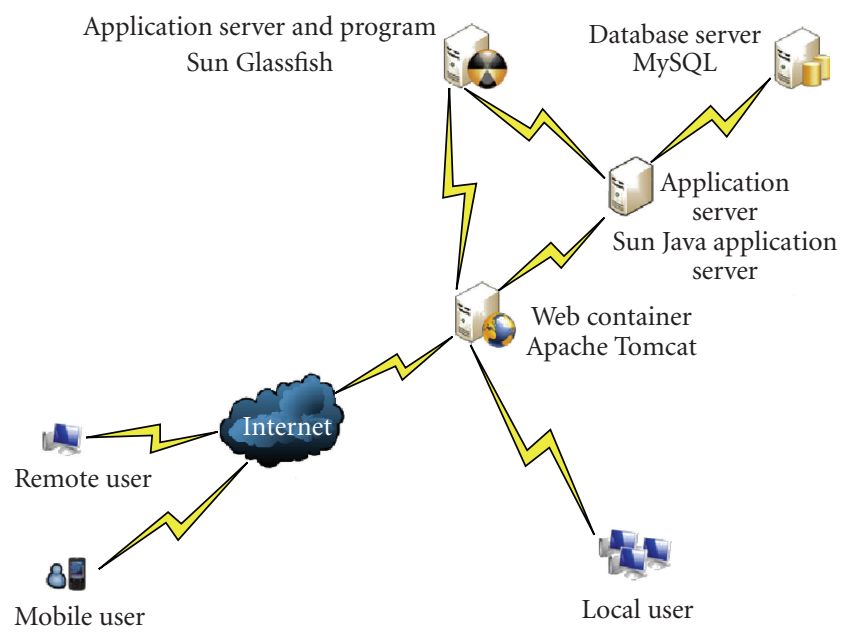

FIgure 2: Physical distribution model.

The present paper discusses both the main features of the ISE and an application of the Platform to a PTS transient test-calculation.

\section{PTS Platform: Main Features}

ISE is an online service that can supply different functions depending of two types of user: administrator, which has mainly management functions, and actual user, which performs calculations. Each user may access to ISE, once username and password were typed. Administrator can manage, modify and erase each account and verify the correct utilization of ISE, monitoring simulation variables and checking for possible simulation aborts.

ISE must be in compliance with some non functional requirements, namely: it must be reliable, because data must be always consistent and they must be saved even when system crashes; besides data must be classified and available only for registered users; then, best performance must be assured and finally, graphic interface and procedures must be user friendly. A robust, safe and efficient platform can be developed by implementing Java Enterprise Edition (J2EE) technology, because it uses object oriented Java language and it is constantly updated by the most important software companies devoted to information technology, such as Sun (creator and developer of Java language), IBM, Oracle and BEA. J2EE is an environment that eases webbased distributed software development, by using a multitier technology, where each tier implements a specific service.

Physical distribution model is summarized in Figure 2: database server contains user data and simulation data, namely: input file names, simulation start time and simulation status; machine with Sun Glassfish contains installed programs, routines, input and output files and logic to integrate software and execute it in Java; Sun Java application server contains logic to manage the entire platform, working with database server and Sun Glassfish, in order to fulfill user requests; finally, web container contains presentation logic, namely: graphic user interface.

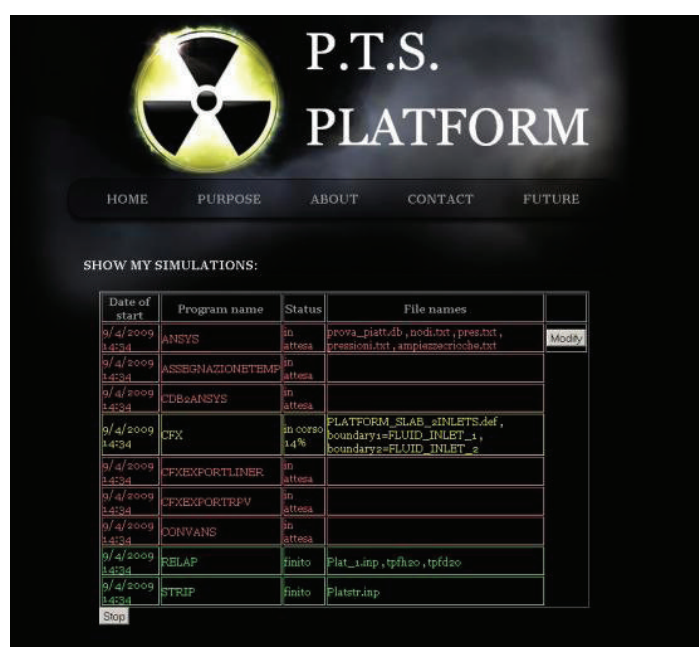

FIgURE 3: Simulation status screen-shot.

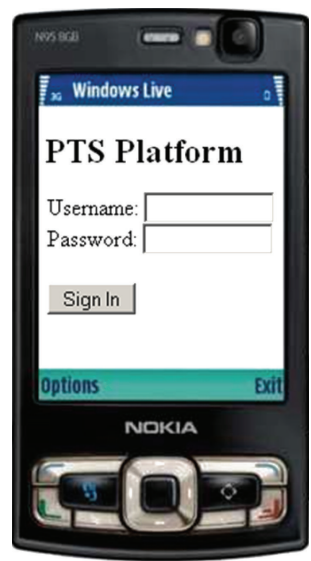

Figure 4: Mobile device interface.

User may access the platform through remote or local connection, by using a web browser (see Figure 3), or through a simplified interface in a mobile device, (see Figure 4 ).

\section{PTS Platform: Data Transfer}

ISE shall interface different existing codes as described in Figure 5: once assigned boundary and initial conditions, Relap5-3D simulation is performed, to evaluate main thermodynamic variables (fluid temperatures, pressure, void fraction, etc.) in the entire NPP for a specified PTS transient. Relap5-3D output data are then selected by using a Strip procedure, only data useful for PTS analysis are saved and converted into CFX input format: mass flow rate and fluid temperature at CL the inlet nozzles. These data constitute boundary and initial conditions for CFD calculation, that is, performed in the CFX solver in order to simulate with more detail single phase mixing phenomena in the RPV downcomer.

CFX output data must be selected, because structural mechanics analysis needs only to acquire data about wall temperature profile and fluid pressure against wall, during 


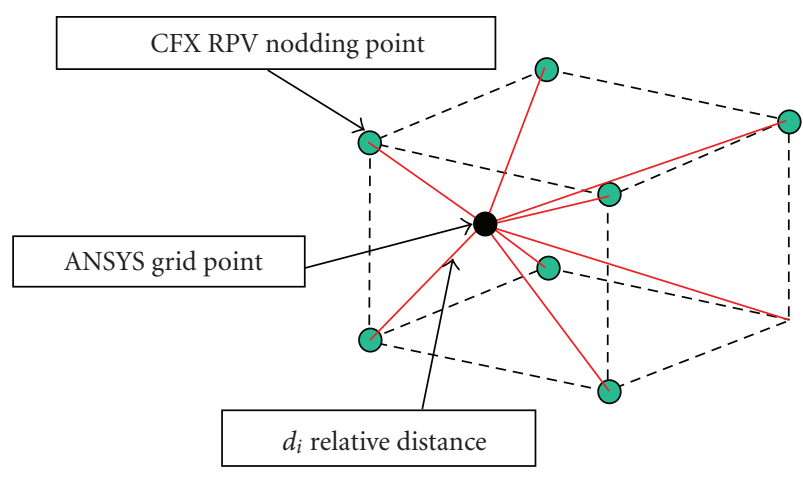

FIgURE 5: ANSYS-CFX coupling technique.

the simulated transient. Therefore, while pressure data are given by Relap5-3D strip, only temperature data through RPV liner and carbon steel material in the downcomer region are selected from CFX solver output data and converted into ANSYS Multiphysics input format.

A CFX-ANSYS subroutine is needed to transfer temperature data from CFX nodes to ANSYS nodes, because these codes use different optimized meshes of the same solid domain and different numerical approaches: Finite Volumes (FVs) and Finite Elements (FEs), respectively.

So a flexible CFX-ANSYS coupling technique is needed, to transfer temperature values calculated in the CFX node to ANSYS nodes, wherever they are placed. An ANSYS node may get the temperature of the nearest CFX point or may get the temperature Length Weight Mean (LMW) calculated using its eight nearest CFX nodes (see Figure 5), the first method is satisfactory only if the two models have a huge number of nodes (order of magnitude of million of nodes).

With this method temperature data can be imported in the ANSYS solver (see [4]), so structural mechanics calculations can be performed for both thermal and mechanical loads. ANSYS output data are then selected in order to know only the mechanical and thermal stress profile through the RPV carbon steel thickness by the coldest ANSYS node of the downcomer, during the selected transient; these data must be converted in a proper format, to perform fracture mechanics calculations thanks to a Mathcad routine. Output data passed from ANSYS to Mathcad are the circumferential (hope) stresses computed on the crack border for axial crack, and the axial stress for circumferential crack. Mathcad output data (KI) and the material KIc are then plotted as function of time or temperature at the crack tip.

\section{Test Calculation}

A test calculation of the PTS platform was performed for ATUCHA II NPP, that is, a pressurized, heavy water cooled, heavy water moderated reactor with a net electrical power of 692 MW (2161 MWth).

The reactor system consists of the RPV (see Figure 6), its internals and the control shutdown equipment. The coolant is circulated through the two parallel reactor coolant loops by two Main Coolant Pumps (MCPs), it enters the RPV via two inlet nozzles and flows through the annular downcomer between the pressure vessel and moderator tank walls. After arriving to the RPV bottom, the coolant flows upward through the coolant channels and, after joining with the closure head bypass and gap flows, leaves the RPV from two reactor outlet nozzles. The coolant flows from the RPV through the reactor coolant piping to the two Steam Generators (SG), where the power supplied by the reactor and coolant pumps is removed from the coolant. The primary side pressure of the reactor, reactor coolant and moderator system is maintained by the pressurizing system. The Pressurizer (PRZ) is connected to the reactor coolant system by the surge line, which is connected to the Hot Leg (HL) of reactor coolant line. The reactor coolant system consists further of two loops, each comprising one SG, one MCP and the interconnecting reactor coolant piping together the pressurizing and PRZ relief system. The two identical, parallel reactor coolant loops have the task of transferring the power generated in the RPV to the SG.

The PTS initiating event considered in this testcalculation is an Intermediate Break LOCA with $200 \mathrm{~cm}^{2}$ break area in CL2, case A. All the emergency systems are supposed to be available and working and the only failure is the break opening.

A Relap5-3D nodalization of ATUCHA II NPP has been developed by GRNSPG group for PTS analysis. In particular for the downcomer region, two multidimensional components available in the Relap5-3D System Thermal-Hydraulics (SYS TH) code have been used. The multidimensional component was developed to allow the user to model more accurately the multidimensional hydrodynamic features of reactor applications, primarily in the vessel (i.e., core, downcomer) and steam generator. The multidimensional component defines a one, two, or three dimensional arrays of volumes and the internal junctions connecting the volumes.

The fluid in the primary side is in single phase; therefore the results of the Relap5-3D calculation of the selected transient have been used as boundary conditions for the CFX code for a more detailed calculation of the mixing phenomena occurring in the downcomer. The CFX model developed of ATUCHA II NPP downcomer and RPV is very accurate: the computational domain consists of a solid domain (Carbon steel + stainless steel liner) with a total of about 0.63 million nodes and a fluid domain (about 1.7 million nodes); the assembled computational domain, along with its components, is shown in Figure 7.

Structural mechanics model for ATUCHA II NPP RPV is a shell made of two materials: carbon steel in the external part and stainless steel liner in the inner part. The RPV is equipped with hemispherical closure and bottom head, which contains an hemisphere full of Carbon Steel, called "Filler". Thickness through downcomer wall is constant between lower and upper welding lines; thickness increases above the upper welding line and then it remains constant up to the upper head. The RPV has 12 penetrations.

The complete structural mechanics model for ATUCHA II NPP RPV is shown in Figure 8.

RPV is fixed to the basement through 4 double-T beams, which are welded to the RPV at about the same height of Cold/Hot Legs, as shown in Figure 9. 


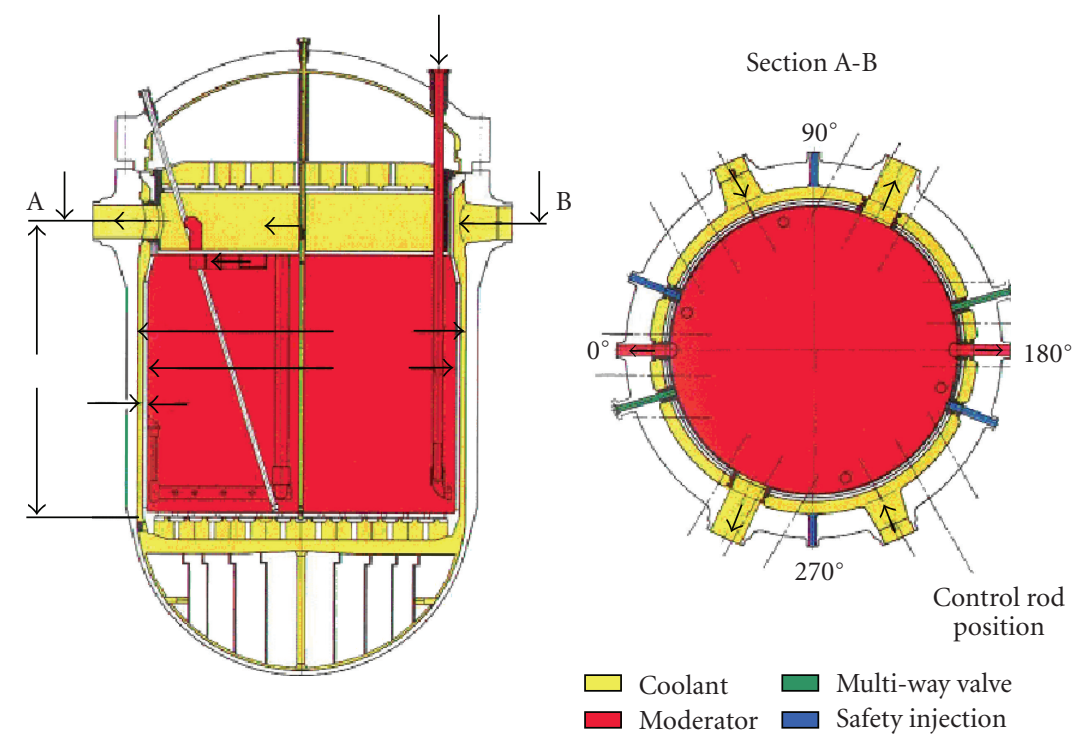

FIgURe 6: ATUCHA II Reactor Pressure Vessel vertical and horizontal sections.

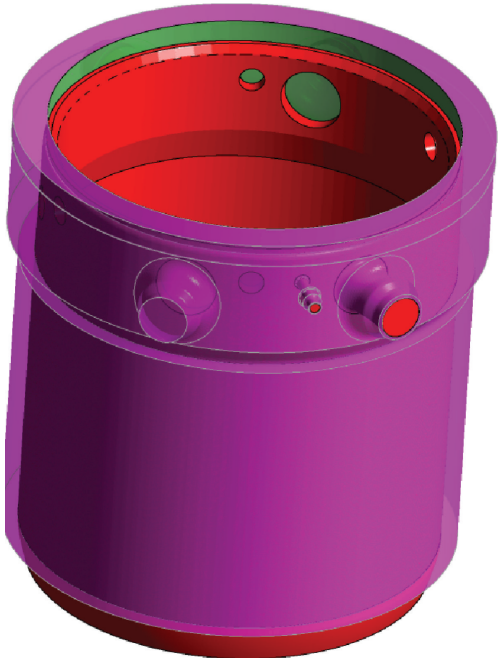

Figure 7: CFX model overall assembly.

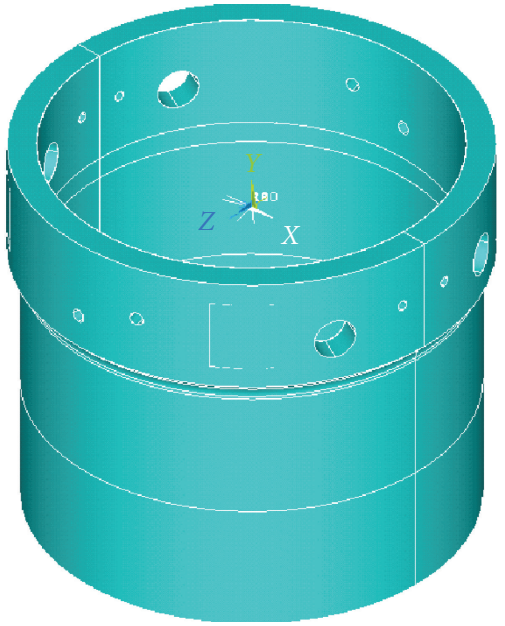

FiguRE 8: Structural mechanics model overall assembly.
For structural mechanics calculations thermal and mechanical loads are considered.

Thermal loads are due to the temperature difference between a reference condition (constant everywhere) and the actual condition in a specified time step; 5 different time steps have been analyzed during the selected transient, with a constant interval between two consecutive time steps.

Mechanical loads are mainly due to:

(i) pressure of fluid on the internal walls (see Figure 10);

(ii) weight of filler in the lower part (bottom head);

(iii) gravity: $g=9.81 \mathrm{~m} / \mathrm{s}^{2}$.

Two typical nuclear grade materials have been used for our test-calculation:

(i) Carbon steel;

(ii) Stainless steel.
The main results of this test are reported in Figures 11 and 12.

Temperature profile on downcomer inner surface (Figure 11) shows an asymmetric reduction in temperature due to CL1 and CL2 cold water injection and emergency systems injection, while the other zones remain hotter. Temperature profile imported in ANSYS (Figure 12) is coherent with CFX results, because the cold water injections take place in the inner part, so that it is colder than the outer part; that is, why the temperature increases going from inside to outside.

Von Mises stresses shown in Figure 13 are due to thermal loads shown in Figure 12, so that stresses are higher in the zones where the decrease in temperature is greater, (i.e., close to the injection zone) and close to the geometrical discontinuities (i.e., edges and holes), because of stress concentration. 


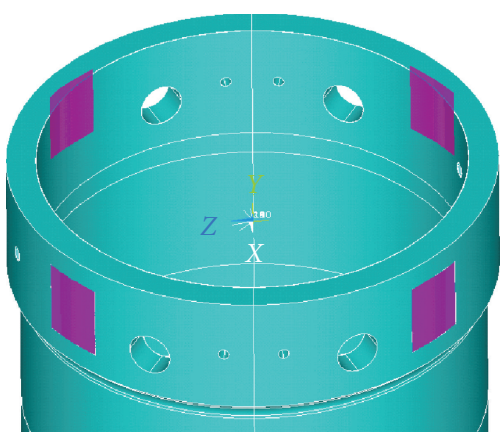

Figure 9: Double-T beams are shown in violet.
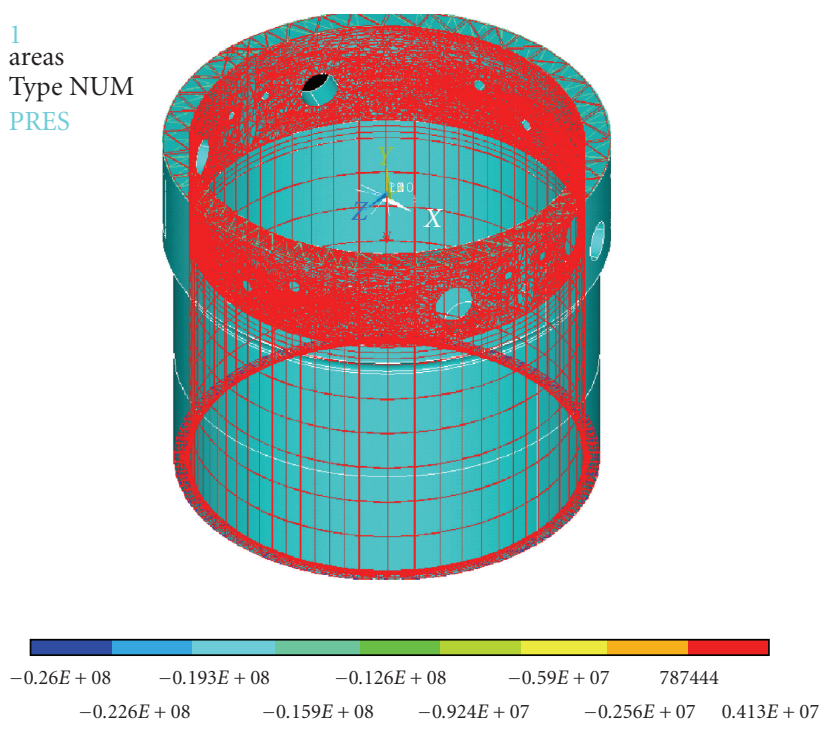

FIGURE 10: Internal pressure and gravity loads.
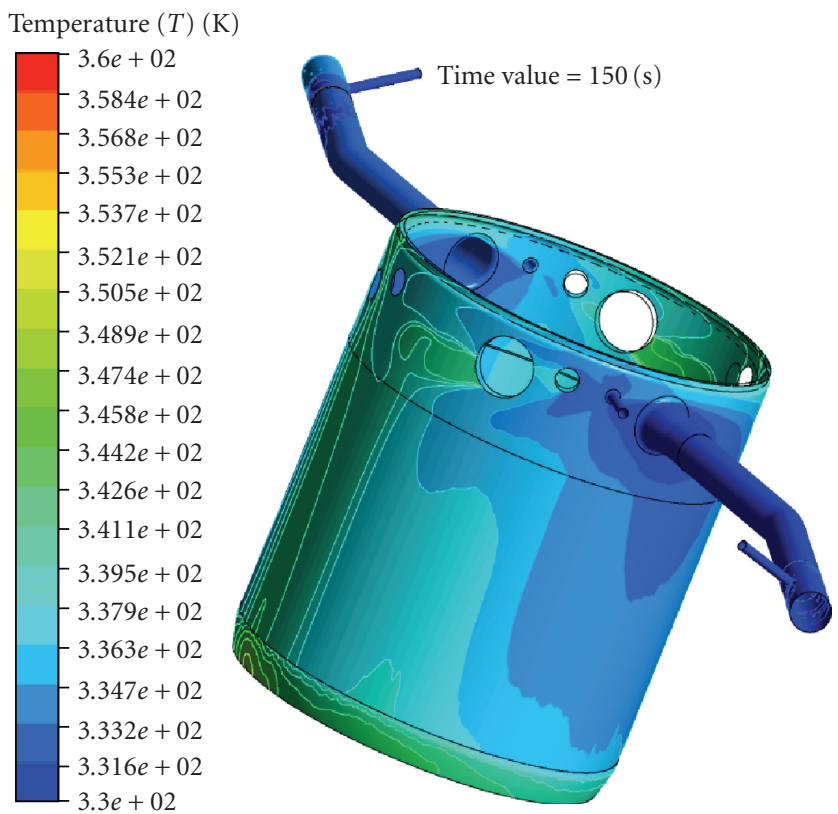

FIGURE 11: CFX temperature profile results on downcomer surface after $150 \mathrm{~s}$.

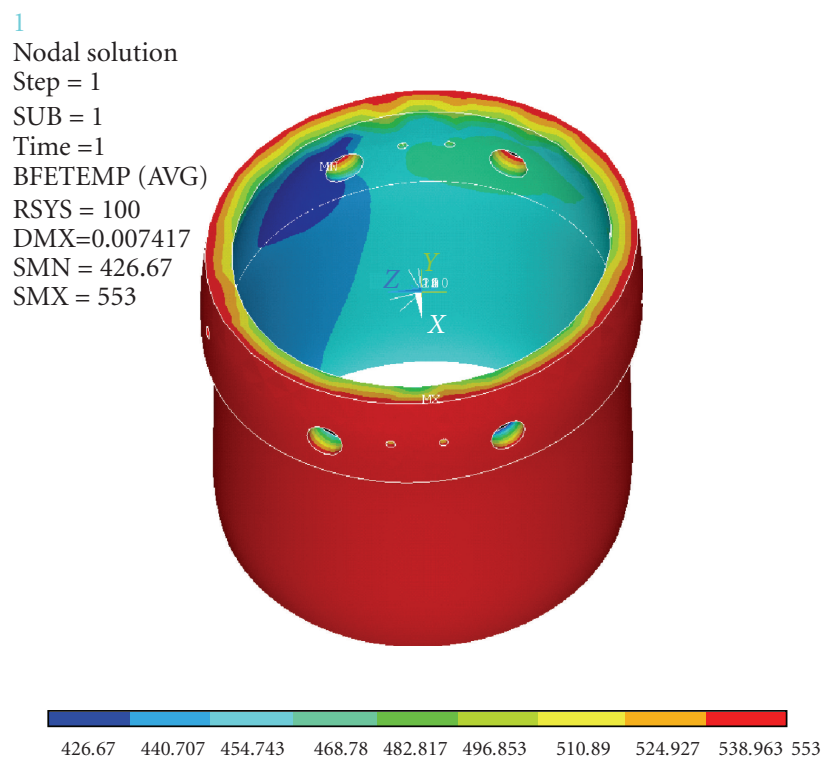

FIGURE 12: ANSYS: temperature profile imported from CFX at a given time-step.

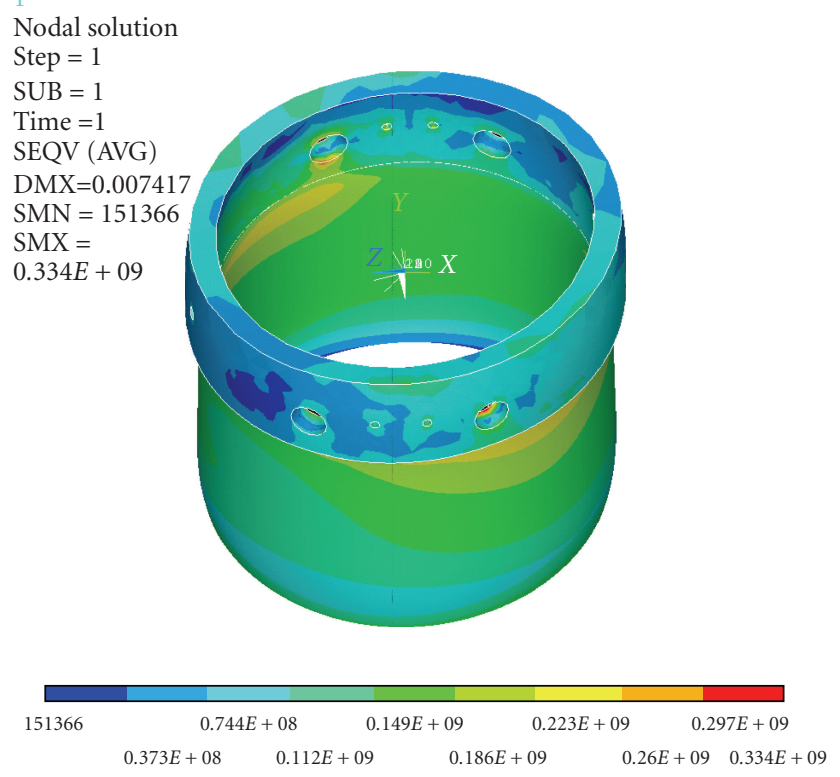

FIGURE 13: Von Mises thermal stresses at a given time-step.

Stresses trough thickness due to mechanical loads are coherent with theory of vessels loaded with internal pressure; see Figure 14. Finally, it can be noted that Stress Intensity Factor (or KI) curve is very far from Fracture Toughness (or KIc) curve; see Figure 15. (Note that the KIc curve refers to Atucha I base material.)

From this test-calculation, we can assume that the selected transient is not relevant for PTS analysis of ATUCHA II NPP. 


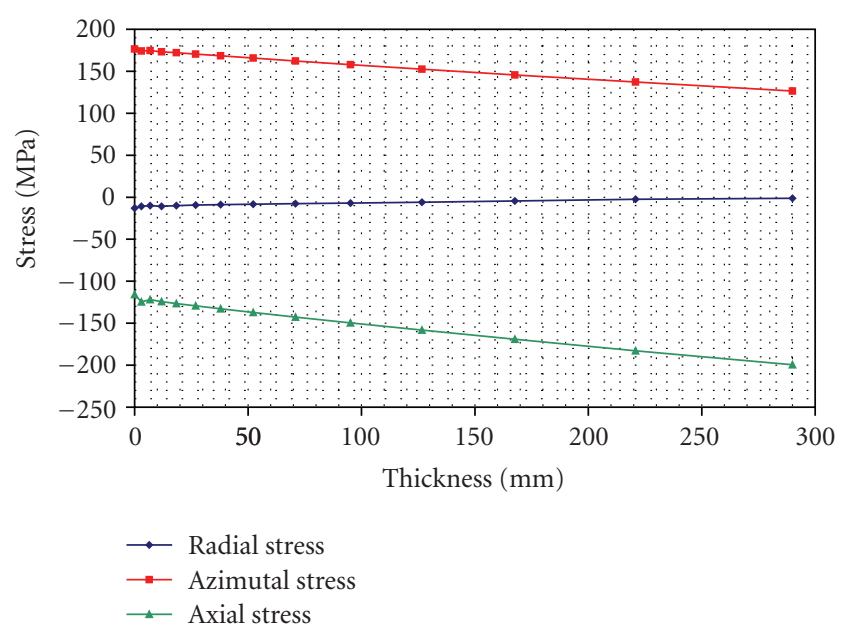

Figure 14: Mechanical stress through thickness.

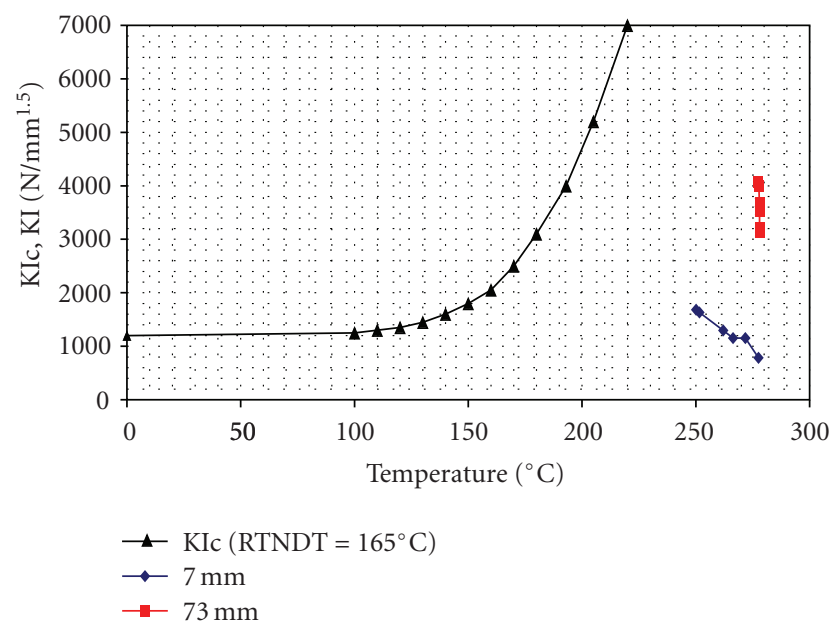

FIGURE 15: KI and KIc versus temperature.

\section{Conclusions}

This paper describes the development of an ISE able to perform PTS analyses through the implementation of a methodology developed at the University of Pisa, together with an application to a test-calculation for ATUCHA II NPP.

A chain of codes (Relap5-3D, CFX, ANSYS) is needed for a complete PTS analysis, therefore the ISE, called PTS Platform is able to connect those codes each other and to calculate the stress intensity factor KI, once the boundary and initial conditions have been given in input to the software. It means that, starting from the boundary conditions of the SYS TH code till the calculation of the KI, a number of interfaces have been built and implemented for transferring the data from one code to another.

The version of the PTS platform presented, developed by GRNSPG is only the first prototype of such integrated software tool, therefore it widely fulfills the initial requirements, but further improvements and additional features are needed, related to some aspects: for example it could be useful to run automatically a sequence of PTS transients, where boundary and initial conditions for each transient are read from a proper input file.

Another development will be the implementation of an automatic results after processing, integrated with a simple interface to help user to choose variables to plot. Obviously, users' feedbacks will be taken into great consideration to correct possible bugs or to implement new features.

\section{References}

[1] T. Fett and D. Munz, Stress Intensity Factors and Weight Functions, Computational Mechanics Publications, Southampton, UK, 1997.

[2] D. Mazzini, D. Areneo, M. Beghini, and F. D'Auria, "Fracture mechanics analysis of generic WWER-1000 RPV in PTS event," in Proocedings of International Congress on Advances in Nuclear Power Plants (ICAPP '03), pp. 80-90, Cordoba, Spain, May 2003.

[3] The RELAP5-3D(C) Code Development Team, "Relap5-3D(C) Code Manual Volume I: Code Structure, System Models and Solution Methods," February 2001.

[4] "ANSYS 11.0 Manual User Manual," (embedded in the software package), 2007. 

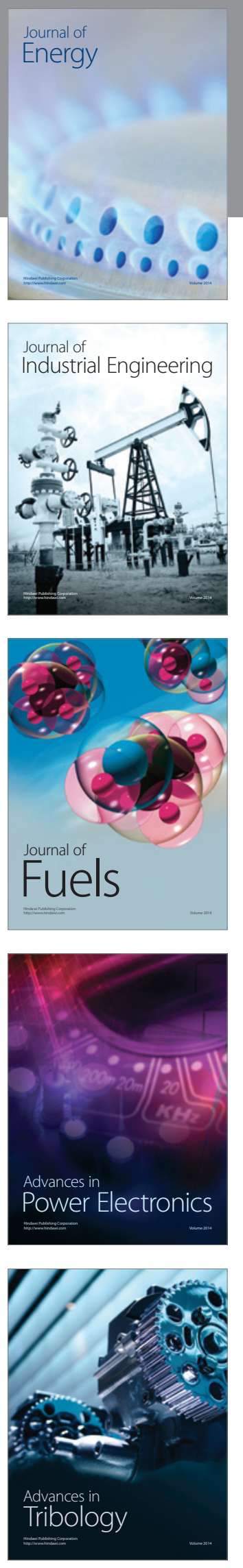
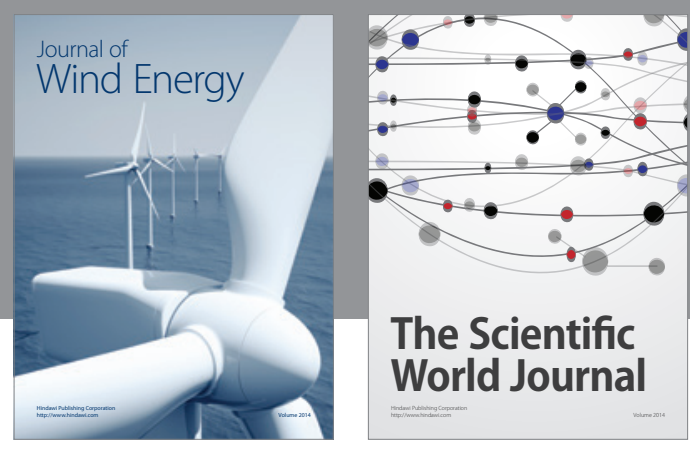

The Scientific World Journal

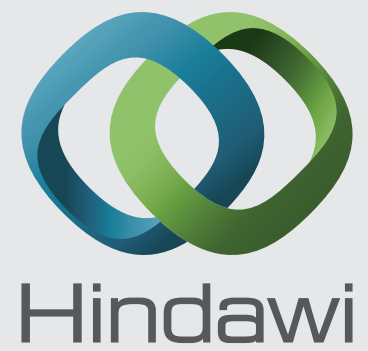

Submit your manuscripts at http://www.hindawi.com
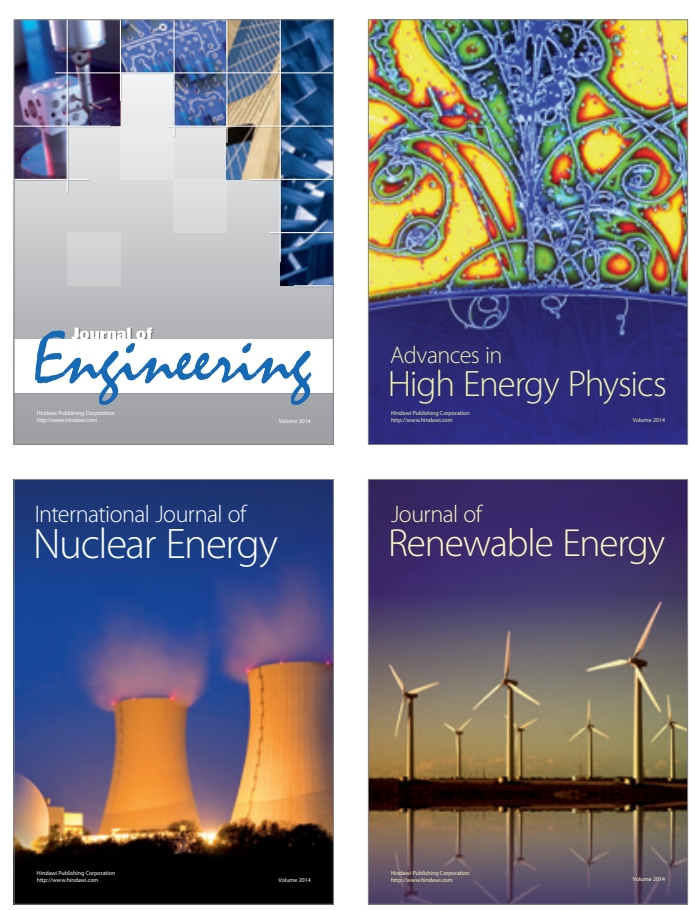

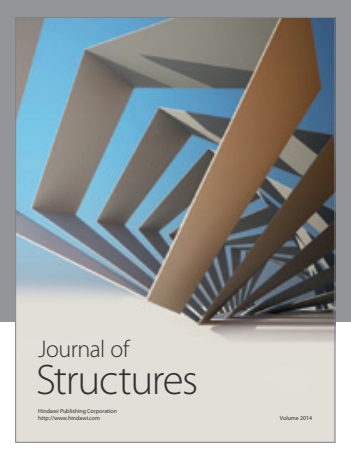

Rotating
Mechinery
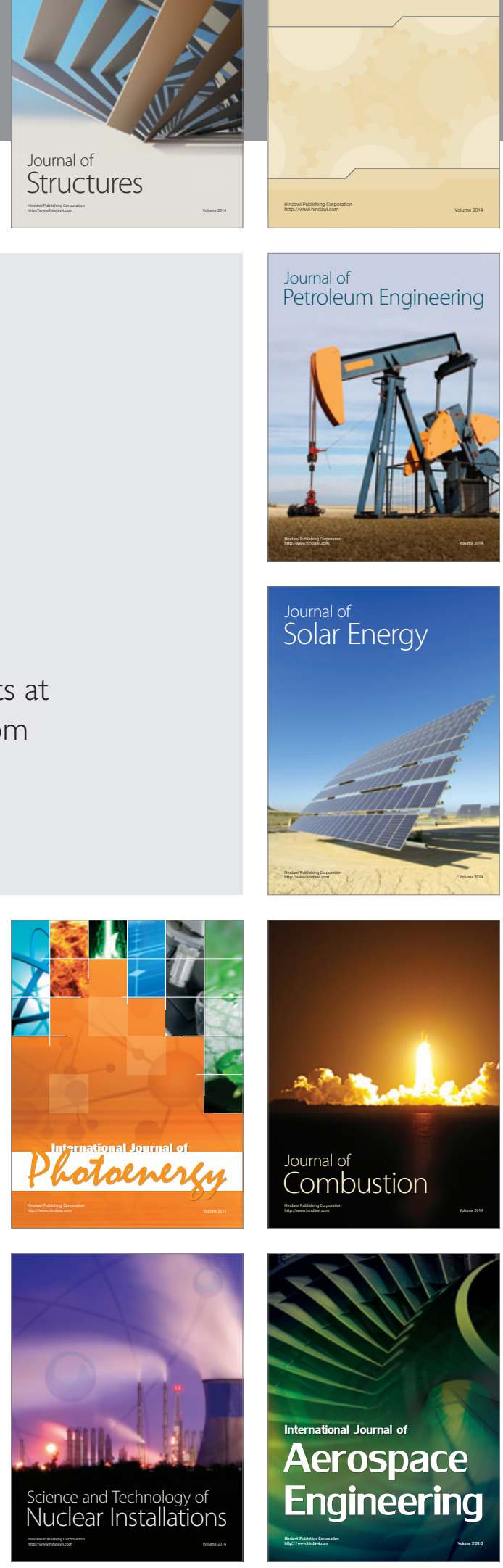